\title{
Metabolic adaptation is associated with less weight and fat mass loss in response to low-energy diets
}

Catia Martins ${ }^{1,2,3^{*}}$, Jessica Roekenes ${ }^{1}$, Barbara A. Gower ${ }^{3}$ and Gary R. Hunter ${ }^{3}$

\begin{abstract}
Background: The practical relevance of metabolic adaptation remains a controversial issue. To the best of our knowledge, no study has properly evaluated the role of metabolic adaptation in modulating weight loss outcomes. Therefore, the aim of this study was to determine the association between metabolic adaptation, at the level of resting metabolic rate (RMR), and weight and fat mass (FM) loss after low-energy diets (LED), after adjusting for dietary adherence and other confounders.

Methods: 71 individuals with obesity (BMI: $34.6 \pm 3.4 \mathrm{~kg} / \mathrm{m}^{2}$; age: $45.4 \pm 8.2$ years; 33 males) were randomized to one of three $1000 \mathrm{kcal} /$ day diets for 8 weeks. Body weight, FM and fat-free mass (FFM) (air displacement plethysmography), RMR (indirect calorimetry) and physical activity level (PAL) (armbands) were measured at baseline and at week 9. Metabolic adaptation at week 9 was defined as measured RMR minus predicted RMR at week 9 . An equation to predict RMR was derived from baseline data of all participants that were part of this analysis and included age, sex, FM and FFM as predictors. Dietary adherence was calculated from RMR, PAL and body composition changes. Linear regression was used to assess the potential role of metabolic adaptation in predicting weight and FM loss after adjusting for dietary adherence, average PAL, sex, baseline FM and FFM and randomization group.

Results: Participants lost on average $14 \pm 4 \mathrm{~kg}$ of body weight (13 $\pm 3 \%$ ) and presented with metabolic adaptation $(-92 \pm 110 \mathrm{kcal} /$ day, $P<0.001)$. Metabolic adaptation was a significant predictor of both weight $(\beta=-0.009$, $P<0.001)$ and FM loss $(\beta=-0.008, P<0.001)$, even after adjusting for confounders $\left(R^{2}=0.88,0.93\right.$, respectively, $P<0.001$ for both). On average, an increase in metabolic adaptation of $50 \mathrm{kcal} /$ day was associated with a $0.5 \mathrm{~kg}$ lower weight and FM loss in response to the LED.
\end{abstract}

Conclusion: In individuals with obesity, metabolic adaptation at the level of RMR is associated with less weight and FM loss in response to LED.

Trial registration ID: NCT02944253.

Keywords: Metabolic adaptation, Adaptive thermogenesis, Resting metabolic rate, Weight loss

*Correspondence: catia.martins@ntnu.no

1 Obesity Research Group, Department of Clinical and Molecular Medicine, Faculty of Medicine and Health Sciences, Norwegian University of Science and Technology (NTNU), Forsyningssenteret, Prinsesse Kristinas Gate 5, 7030 Trondheim, Norway

Full list of author information is available at the end of the article

\section{Background}

Metabolic adaptation, a reduction in energy expenditure below predicted levels in response to weight loss, has been one of the most controversial issues in the Obesity field, both in terms of its real existence, as well as clinical relevance [1-7]. Recent findings from our group suggest that metabolic adaptation depends greatly on the energy original author(s) and the source, provide a link to the Creative Commons licence, and indicate if changes were made. The images or other third party material in this article are included in the article's Creative Commons licence, unless indicated otherwise in a credit line to the material. If material is not included in the article's Creative Commons licence and your intended use is not permitted by statutory regulation or exceeds the permitted use, you will need to obtain permission directly from the copyright holder. To view a copy of this licence, visit http://creativecommons.org/licenses/by/4.0/. The Creative Commons Public Domain Dedication waiver (http://creativeco mmons.org/publicdomain/zero/1.0/) applies to the data made available in this article, unless otherwise stated in a credit line to the data. 
balance (EB) status of the participants [8]. Despite being significant during negative EB (on average $100 \mathrm{kcal} / \mathrm{d}$ ), metabolic adaptation is of minor magnitude (on average $50 \mathrm{kcal} /$ day) when measurements are done under conditions of weight stability following weight loss $[8,9]$. This is in line with previous findings showing that the existence or not of metabolic adaptation depends on study design, with cross-sectional studies, comparing obesereduced individuals to body mass index (BMI)-matched controls, not reporting metabolic adaptation [10-14], while longitudinal studies report metabolic adaptation [15-20], likely because measurements are taken during negative EB.

Despite the abundance of studies, discussed above, on the existence and magnitude of metabolic adaptation, less is known regarding its clinical relevance. Even though several studies have suggested that metabolic adaptation could be a potential explanatory mechanism for resistance to weight loss and/or an important driver of longterm weight regain (relapse) [1-5], no study has, to our knowledge, shown metabolic adaptation to be associated with less weight loss or more weight regain. In fact, we [8, 9] and others [18] have reported metabolic adaptation, at the level of RMR, not to be a risk factor for weight regain. However, we have also recently shown in premenopausal women with overweight, that metabolic adaptation with a 16\% weight loss increases the length of time necessary to achieve weight loss goals [21]. Taken together, these results suggest that metabolic adaptation during negative EB may be relevant to weight loss success.

However, it remains to be investigated if metabolic adaptation is associated with worse weight loss outcomes. Therefore, the primary aim of the present analysis was to determine if metabolic adaptation, at level of RMR, was associated with weight and/or fat mass (FM) loss, after adjusting for dietary adherence and other confounders, in a population of individuals with obesity. We hypothesized that metabolic adaptation would be associated with less weight and FM loss in response to lowenergy diets (LED).

\section{Methods}

\section{Participants}

Participants in this analysis are part of a large weight loss study (ASKED - Ketosis and Appetite Suppression), aiming to identify the maximum carbohydrate $(\mathrm{CHO})$ intake still associated with appetite suppression in a LED.

The original study enrolled adult (18-65 years old) healthy volunteers, men and women, with obesity $\left(B M I \geq 30 \mathrm{~kg} / \mathrm{m}^{2}\right)$, weight stable $(<2 \mathrm{~kg}$ variation in weight within the last 3 months), not currently dieting to lose weight and not using any medications known to affect body weight, appetite or metabolism. Given that both RMR and appetite of normally ovulating women has been shown to vary across the menstrual cycle [22, 23], but not in those who take oral contraception [24], we only included post-menopausal women, women taking oral contraceptives or those with a normal menstrual cycle ( $28 \pm 2$ days) in the study. This was done to ensure that all measurements were taken in the same phase of the menstrual cycle.

The study was approved by the local ethical committee (REK Midt-Norge, Norway) and all participants provided informed consent before participation. The trial was registered on the 25 October 2016, in Clinicaltrials. gov (NCT02944253), https://clinicaltrials.gov/ct2/show/ NCT02944253.

\section{Study design}

This weight loss study was a randomized control trial with repeated measurements. All participants, both men and women, were randomized to one of three isocaloric $1000 \mathrm{kcal} /$ day LEDs containing varying amounts of $\mathrm{CHO}(70,100$, and $130 \mathrm{~g} \mathrm{CHO}$ in each group) and a fixed amount of protein (75 g/day). Participants were provided with modular products built specifically for this study (Food Innovation, Oslo, Norway), including shakes and soups, and were encouraged to consume up to $100 \mathrm{~g} /$ day of low-starch vegetables and were allowed ad libitum consumption of non-caloric beverages. Participants followed this diet for 8 weeks at the Regional Center for Obesity Research and Innovation (ObeCe) in Trondheim, Norway. For more details about the intervention, please see Martins et al. 2020 [8]. A flowchart of the study can be seen in Fig. 1.

\section{Data collection}

\section{Measures of compliance}

Diet For the entire duration of the trial, participants attended weekly individual 20-min consultations with study personnel to monitor food intake, body weight (SECA 877 body weight scale, SECA, Hamburg, Germany) and ketosis in urine (acetoacetic acid concentration in urine measured using Ketostix reagent strips (Ascensia Diabetes Care, Basel, Switzerland) and blood ( $\beta$-hydroxybutyrate concentration in blood measured using FreeStyle Precision Neo (Abbott Laboratories, Quebec, Canada)).

Participants were asked to fill out and submit paperbased food diaries every week detailing all they had consumed each day and to note any side effects they might have experienced. Weekly food diaries obtained from all participants at weeks 2,5 and 8 of the study were plotted into an online diet planner, Kostholdsplanleggeren (Norwegian Directorate of Health and the Norwegian Food Safety Authority, Oslo, Norway) to estimate actual 


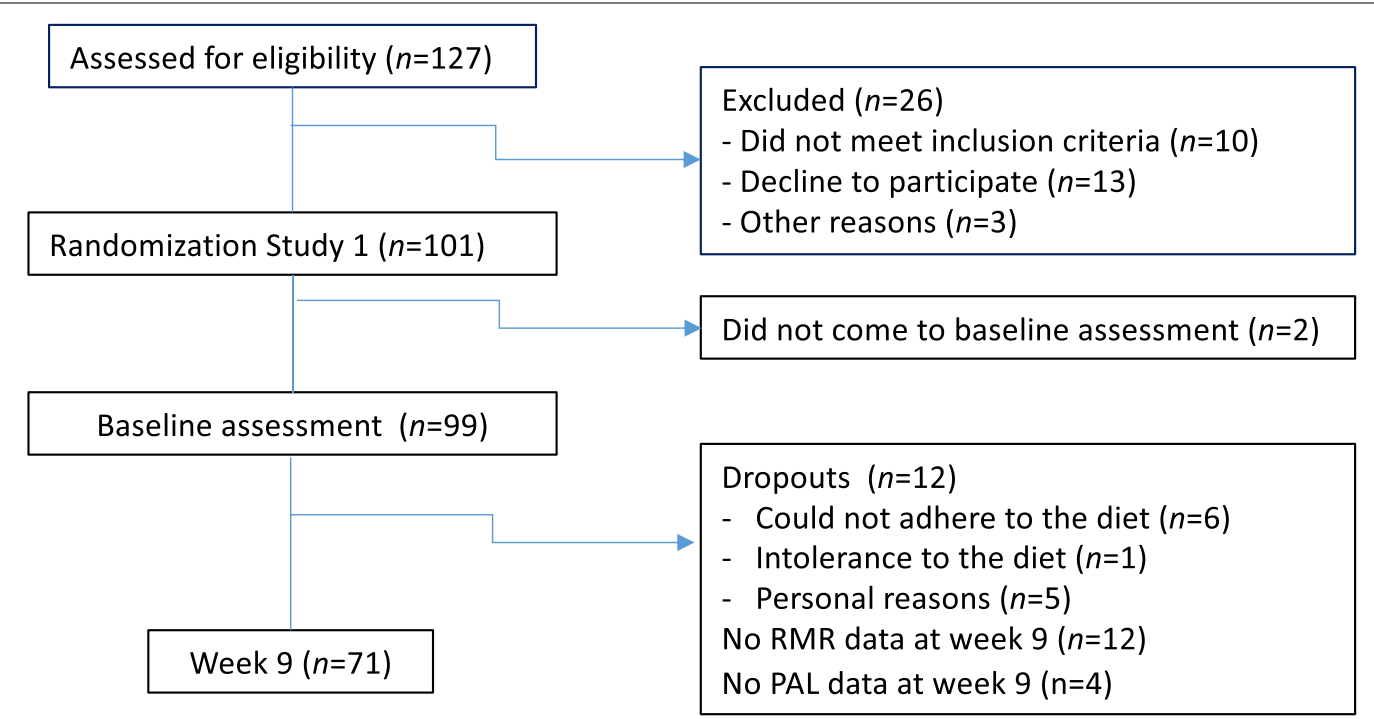

Fig. 1 Flowchart of the study. RMR: resting metabolic rate, PAL: physical activity level

daily average energy and macronutrient intake during the weight loss phase of the trial.

Physical activity Participants were asked not to change their physical activity (PA) levels during the study. To check for compliance, participants were asked to wear armbands (SenseWear) for 7 days at baseline (week before the start of the study) and at week 8 . These data were considered valid if the participants wore the device for $\geq 4$ days, including at least one weekend day, more than $95 \%$ of the time [25]. Information on physical activity level (PAL) was extracted from the armbands and provided an indication of an individual's daily physical activity $(<1.40$ indicates extremely inactive, 1.40-1.69 indicates sedentary, 1.70-1.99 indicates moderately active, 2.00-2.40, indicates vigorously active and $>2.40$ indicates extremely active).

\section{Outcome variables}

The following measurements were conducted at baseline and week 9 (W9) (immediately after weight loss, in negative energy balance), while the participants were in the fasting state and immediately after they had voided in the morning:

\section{Body weight, fat mass and fat-free mass}

Body weight and composition (fat mass $(\mathrm{kg})$ and fat-free mass $(\mathrm{kg})$ ) were determined by whole body air displacement plethysmography (BOD POD, COSMED, Albano Laziale, Italy).

\section{Resting metabolic rate}

RMR was measured by indirect calorimetry (Vmax Encore 29 N; Care Fusion, Baesweiler, Germany) using a canopy system and standard operating procedures [26].

\section{Adherence to diet}

Dietary adherence was estimated using a modified version of the original protocol proposed by del Corral and colleagues [27]. First, total energy expenditure (TEE)) was calculated for each individual participant using two methods: (1) RMR $x$ PAL derived from armbands and (2) $R M R \times 1.4$. The results from these two methods were averaged to derive one TEE value for each individual. The reason for this approach is that individuals are likely to increase their PA levels when they wear monitoring devices [28]. TEE at baseline and week 9 was calculated (as described above) and the average of both (TEE baseline and TEE week 9) used. The expected daily kilocalorie loss was calculated as average TEE (baseline and week 9 for each individual)-actual daily average energy provided by the diet (food diaries). Second, to convert losses of FM and FFM (from BOD POD) to energy (i.e. kilocalories lost), we used energy coefficients of 9.3 and $1.1 \mathrm{kcal} / \mathrm{g}$, respectively $[29,30]$ : actual daily kilocalorie loss $=[\mathrm{FM}$ lost $(\mathrm{g}) \times 9.3 \mathrm{kcal} / \mathrm{g}]+[\mathrm{FFM}$ lost $(\mathrm{kg}) \times 1.1 \mathrm{kcal} / \mathrm{g}]$. Third, knowing the actual daily kilocalorie loss and the expected daily kilocalorie loss, we calculated the daily kilocalorie discrepancy, an index of dietary adherence: daily kilocalorie discrepancy $=$ actual daily kilocalorie loss-expected daily kilocalorie loss. A daily kilocalorie discrepancy of zero represents $100 \%$ adherence. A positive number 
would indicate a greater than expected daily kilocalorie loss, whereas a negative number would suggest less than expected daily kilocalorie loss. Fourth, we expressed dietary adherence in relative terms: percent daily kilocalorie adherence $=($ actual daily kilocalorie loss/expected daily kilocalorie loss) $\times 100$.

\section{Statistical analysis}

Only participants with data available at baseline and W9 were included in this analysis.Statistical analysis was performed with SPSS version 22 (SPSS Inc., Chicago, IL), data presented as mean \pm SD and statistical significance set at $P<0.05$. Changes in body weight and composition over time were assessed with paired t-tests. The presence of metabolic adaptation was tested by paired t-tests, comparing measured RMR (RMRm) and predicted RMR (RMRp) at the same time points. An equation to predict RMR was derived from baseline data of all participants that were part of this this analysis and included age, sex, FM and FFM as predictors.

$$
\begin{aligned}
\operatorname{RMRp}(\mathrm{kcal} / \mathrm{d})= & 505.945+[110.894 \times \operatorname{sex}(1 \text { for females } \\
& \text { and } 2 \text { for males })]+[0.402 \times \text { Age }(\text { years })] \\
& +[5.616 \times \mathrm{FM}(\mathrm{kg})]+[15.213 \times \mathrm{FFM}(\mathrm{kg})] . \\
R^{2}=0.79 ; P & <0.001
\end{aligned}
$$

Linear Regression models were used to estimate the relationship between weight and FM loss (in $\mathrm{kg}$ ) at week 9 and metabolic adaptation, after adjusting for diet group (70, 100 and $130 \mathrm{~g} \mathrm{CHO/day,} \mathrm{as} \mathrm{a} \mathrm{categorical} \mathrm{variable)}$ and varaiables known to modulate weight and FM loss outcomes, such as adherence to the diet [27], average PAL [31], sex and baseline body composition (FM and FFM in $\mathrm{kg}$ ) [32].

Additional analysis, including interaction terms for age, sex and BMI, was performed by introducing an interaction between metabolic adaptation and each of the variables in model, in addition to the other variables (metabolic adaptation, age, sex, BMI, carbohydrate group, PAL, dietary adherence and FFM). FM had to be removed from this model, as FM and BMI are highly correlated and, therefore, their regression coefficients might cancel each other out (multicollinearity).

\section{Results}

Seventy-one adult participants (38 males, 54\%) with obesity were included in the present analysis, with an average age of $45 \pm 8$ years and an average BMI of $35 \pm 3 \mathrm{~kg} / \mathrm{m}^{2}$ at baseline (see Table 1).

Participants lost, on average $14.1 \pm 0.4 \mathrm{~kg}$ of body weight $(13.2 \pm 2.8 \%)$. FM and FFM $(\mathrm{kg})$ were both
Table 1 Participant characteristics at baseline and week 9

\begin{tabular}{lclr}
\hline & Baseline & Week & P value \\
\hline Age (years) & $45.4 \pm 8.2$ & & \\
Weight (kg) & $104.0 \pm 14.6$ & $90.1 \pm 11.6$ & $<0.001$ \\
BMI (kg/m²) & $34.6 \pm 3.4$ & $30.3 \pm 3.0$ & $<0.001$ \\
FM (kg) & $43.3 \pm 9.1$ & $32.4 \pm 8.6$ & $<0.001$ \\
FFM (kg) & $60.0 \pm 10.9$ & $57.6 \pm 9.9$ & $<0.001$ \\
PAL & $1.50 \pm 0.16$ & $1.48 \pm 0.14$ & 0.369 \\
RMRm (kcal/day) & $1856 \pm 249$ & $1654 \pm 204$ & $<0.001$ \\
RMRp (kcal/day) & $1856 \pm 221$ & $1746 \pm 193$ & $<0.001$ \\
RMRm-p (kcal/day) & $-0.01 \pm 113$ & $-91.5 \pm 110.4^{* * *}$ & \\
\hline
\end{tabular}

Data presented as mean \pm SD. $P$ value for the comparison between baseline and week 9. BMI: body mass index, FM: fat mass, FFM: fat-free mass, PAL: physical activity level, RMR: resting metabolic rate. ${ }^{* *} P<0.001$ for the comparison between RMRm and RMRp

Table 2 Regression models for predicting weight and fat mass loss at week 9

\begin{tabular}{llll}
\hline Model & B & $\mathbf{R}^{2}$ adjusted & $\boldsymbol{P}$ \\
\hline Weight loss at week 9 & & $88 \%$ & $<0.001$ \\
Intercept & 21.669 & & $<0.001$ \\
Metabolic adaptation & -0.009 & & $<0.001$ \\
Adherence to the diet & -0.069 & $<0.001$ \\
Average PAL & -6.141 & $<0.001$ \\
Sex & -0.304 & 0.711 \\
FM at baseline & -0.093 & $<0.001$ \\
FFM at baseline & -0.277 & $<0.001$ \\
CHO group & 1.490 & $<0.001$ \\
Fat mass loss at week 9 & & $<0.001$ \\
Intercept & 19.275 & $<0.001$ \\
Metabolic adaptation & -0.008 & $<0.001$ \\
Adherence to the diet & -0.079 & $<0.001$ \\
Average PAL & -6.023 & $<0.001$ \\
Sex & -1.932 & $<0.001$ \\
FM at baseline & -0.088 & $<0.001$ \\
FFM at baseline & -0.120 & $<0.001$ \\
CHO group & 1.111 & $<0.001$ \\
\hline
\end{tabular}

Sex: 1 females; 2 males. PAL: physical activity level; CHO: carbohydrate; FM: fat mass; FFM: fat-free mass

significantly reduced at W9 compared with baseline $(43.3 \pm 9.1$ vs $32.4 \pm 8.6 \mathrm{~kg}$ and $60.0 \pm 10.9$ vs $58.3 \pm 10.1 \mathrm{~kg}$, respectively, $\mathrm{P}<0.001$ for both comparisons). RMRm was significantly lower than RMRp after weight loss (W9), resulting in a metabolic adaptation of $-91.5 \pm 110.4 \mathrm{kcal} /$ day $(P<0.001)$ (see Table 1$)$.

Metabolic adaptation after weight loss was a significant predictor of both weight $(\beta=-0.009, P<0.001)$ and FM loss $(\beta=-0.008, P<0.001)$, even after adjusting for dietary adherence, average PAL, and other 
confounders $\left(\mathrm{R}^{2}\right.$ adjusted $=0.88$ and 0.93 , respectively, $P<0.001$ for both) (see Table 2).

The interaction between metabolic adaptation and age, sex and baseline BMI were not significant either in the model to predict weight or fat mass loss.

\section{Discussion}

The present findings represent the first study examining if metabolic adaptation, at the level of RMR, is associated with the magnitude of weight and FM loss in response to LED. We found that the larger the metabolic adaptation (RMRm-RMRp) in absolute terms, the smaller the weight and FM loss seen, independently of age, sex and BMI, and after adjusting for variables known to modulate weight loss responses, namely adherence to the diet, average PAL, sex and baseline body composition. This suggests that metabolic adaptation may worsen weight loss outcomes during LEDs.

In the present analysis, individuals with obesity who had lost an average of $14 \pm 4 \mathrm{~kg}$ (13\%) of body weight, over 8 weeks on a LED, presented with a metabolic adaptation of approximately $-90 \mathrm{kcal} /$ day at week 9 . Our regression model showed that even after adjusting for adherence to the diet, average PAL, sex, baseline body composition, and randomisation group, metabolic adaptation was still a significant predictor of both weight and FM loss. On average, for each $50 \mathrm{kcal} /$ day increase in metabolic adaptation, weight and FM loss were reduced by $0.5 \mathrm{~kg}$. This might not seem of clinical relevance, given that the average metabolic adaptation was only approximately $-90 \mathrm{kcal} /$ day at week 9 . However, in face of the large inter-individual variation in metabolic adaptation seen in the present analysis, ranging from -337 to $+352 \mathrm{kcal} / \mathrm{day}$, that would mean that those with the largest metabolic adaptation (RMRm-RMRp $=-337 \mathrm{kcal} /$ day) would lose $3 \mathrm{~kg}$ less of body weight and $2.7 \mathrm{~kg}$ of FM, compared with those with no metabolic adaptation $(\mathrm{RMRm}-\mathrm{RMRp}=0 \mathrm{kcal} /$ day). This probably helps to explain some of the variation in weight $(-28$ to $-7 \mathrm{~kg})$ and FM $(-19$ to -6$)$ loss seen in response to the LED.

It needs to be taken into consideration that we have only looked at metabolic adaptation at the level of RMR and several studies have shown that metabolic adaptation might in fact be of a larger magnitude at the level of non-resting energy expenditure $[15,16]$. This suggests that overall, metabolic adaptation (regarding TEE) might have an even larger contribution to weight and FM loss in response to LEDs.

From our knowledge only one study has previously reported an association between metabolic adaptation and weight loss outcomes in response to energy restricted diets. Goele and colleagues [33] reported that metabolic adaptation, at the level of RMR, explained
$38 \%$ of the difference between measured and predicted weight loss in 22 out of the 48 women with overweight and obesity who experience metabolic adaptation after a $1000 \mathrm{kcal} /$ day diet [33]. However, this study suffers from several important methodological limitations. First, the association was only seen in a subgroup who experienced metabolic adaptation. Second, metabolic adaptation was defined as a reduction in RMR/ kg of FFM. Despite FFM being the main determinant of RMR, FM also contributes to RMR and should be included in the prediction model. Third, no adjustments were done for dietary adherence or PAL of the participants, both important determinants of weight loss outcomes in response to dietary interventions. The present findings confirm the preliminary findings by Goele and colleagues [33] and expand them further, by showing that metabolic adaptation modulates weight loss outcomes in both men and women with obesity, even after adjusting for dietary adherence and other important confounders. Moreover, we have recently shown that metabolic adaptation, at the level of RMR, increases the length of time necessary to achieve weight loss goals $\left(\mathrm{BMI} \leq 25 \mathrm{~kg} / \mathrm{m}^{2}\right)$, in premenopausal women with overweight [21].

The evidence previously discussed, together with the present findings, suggest that metabolic adaptation might be of clinical relevance. Despite the lack of association between metabolic adaptation and increased risk for weight regain $[8,9,18]$, this phenomenon seems to be of clinical relevance in modulating weight loss in the shortterm, in response to lifestyle interventions. Clinicians need to be aware of inter-individual variations in metabolic adaptation in response to negative EB when evaluating success to weight loss interventions and not assume that differences between measured and predict outcomes result only from "cheating" (reduced compliance to the intervention).

Our study has both strengths and limitations. The main strength is the fact that we have adjusted for important variables known to modulate weight loss outcomes following energy restricted diets, namely dietary adherence [27], PAL [31], as well as sex and body composition at baseline [32]. Second, this analysis includes a heterogeneous sample of both males and females with obesity, with a wide range of BMI (30$43 \mathrm{~kg} / \mathrm{m}^{2}$ ) and age (26-62 years), which is important for generalization purposes. The main limitation of our study is the fact that our estimation of dietary adherence was based on the assumption that energy needs equal RMR x PAL, which is not $100 \%$ acurate. However, the error associated with not having taken into account exercise economy is likely minor, as the SD of exercise economy in sedentary individuals has been shown to be around $12 \%$ of the mean value [34], meaning that in 
the present study differences in economy would only account for an average difference of $40 \mathrm{kcal} /$ day in the estimated TEE. Future studies should use TEE data from doubly labeled water to provide a more accurate estimate of energy needs.

\section{Conclusion}

In conclusion, in individuals with obesity, metabolic adaptation at the level of RMR during a 13\% weight reduction is associated with less weight and FM loss in response to LEDs. This effect is independent of potential confounders, namely sex and initial body composition, as well as adherence to diet and PAL.

\section{Abbreviations}

BMI: Body mass index; CHO: Carbohydrates; EB: Energy balance; FM: Fat mass; FFM: Fat-free mass; LED: Low-energy diet; PAL: Physical activiy level; RMR: Resting metabolic rate; RMRm: RMR measured; RMRp: RMR predicted; TEE: Total energy expenditure.

\section{Acknowledgements}

Not applicable.

\section{Authors' contributions}

The authors' contributions were as follows: CM and JR conceived and designed the study; JR collected the data; CM performed the statistical analysis; CM, JR, BAG and GRH wrote the manuscript; CM had primary responsibility for final content; and all authors: assisted with data interpretation and read and approved the final manuscript.

\section{Funding}

This study was funded by the Norwegian University of Science and Technology (NTNU) (Doctoral grant) and the Liaison Committee for education, research and innovation in Central Norway in partnership with NTNU (running costs). Catia Martins was supported by a Sabbatical grant by the Liaison Committee for education, research and innovation in Central Norway and the NTNU.

\section{Availability of data and materials}

The datasets used and/or analysed during the current study are available from the corresponding author on reasonable request,pending approval by the local Ethics Committee.

\section{Declarations}

\section{Ethics approval and consent to participate}

The study was approved by the local ethical committee (REK Midt-Norge, Norway). All participants provided informed consent before participating in the study.

\section{Consent for publication}

Not applicable.

\section{Competing interests}

The authors declare that they have no competing interests.

\section{Author details}

1Obesity Research Group, Department of Clinical and Molecular Medicine, Faculty of Medicine and Health Sciences, Norwegian University of Science and Technology (NTNU), Forsyningssenteret, Prinsesse Kristinas Gate 5, 7030 Trondheim, Norway. ${ }^{2}$ Centre for Obesity and Innovation (ObeCe), Clinic of Surgery, St. Olav University Hospital, Trondheim, Norway. ${ }^{3}$ Department of Nutrition Sciences, University of Alabama At Birmingham, Birmingham, USA.
Received: 20 January 2021 Accepted: 3 June 2021

Published online: 11 June 2021

\section{References}

1. Dulloo AG, Jacquet J, Montani JP, Schutz Y. Adaptive thermogenesis in human body weight regulation: more of a concept than a measurable entity? Obes Rev. 2012;13(Suppl 2):105-21.

2. Dulloo AG, Schutz Y. Adaptive thermogenesis in resistance to obesity therapies: issues in quantifying thrifty energy expenditure phenotypes in humans. Curr Obes Rep. 2015;4(2):230-40.

3. Celi FS, Le TN, Ni B. Physiology and relevance of human adaptive thermogenesis response. Trends Endocrinol Metab. 2015;26(5):238-47.

4. Rosenbaum M, Leibel RL. Adaptive thermogenesis in humans. Int J Obes. 2010;34(S1):S47-55.

5. Major GC, Doucet E, Trayhurn P, Astrup A, Tremblay A. Clinical significance of adaptive thermogenesis. Int J Obes. 2007;31(2):204-12.

6. Flatt JP. Exaggerated claim about adaptive thermogenesis. Int J Obes (Lond). 2007:31(10):1626; author reply 7-8.

7. Kuchnia A, Huizenga R, Frankenfield D, Matthie JR, Earthman CP. Overstated metabolic adaptation after "the biggest loser" intervention. Obesity (Silver Spring). 2016;24(10):2025.

8. Martins C, Roekenes J, Salamati S, Gower BA, Hunter GR. Metabolic adaptation is an illusion, only present when participants are in negative energy balance. Am J Clin Nutr. 2020;112(5):1212-8.

9. Martins C, Gower BA, Hill JO, Hunter GR. Metabolic adaptation is not a major barrier to weight loss maintenance. Am J Clin Nutr. 2020;112(3):558-65

10. Weinsier RL, Nagy TR, Hunter GR, Darnell BE, Hensrud DD, Weiss HL. Do adaptive changes in metabolic rate favor weight regain in weightreduced individuals? An examination of the set-point theory. Am J Clin Nutr. 2000:72(5):1088-94

11. Weinsier RL, Hunter GR, Zuckerman PA, Darnell BE. Low resting and sleeping energy expenditure and fat use do not contribute to obesity in women. Obes Res. 2003;11(8):937-44.

12. Wyatt HR, Grunwald GK, Seagle HM, Klem ML, McGuire MT, Wing RR, et al. Resting energy expenditure in reduced-obese subjects in the National Weight Control Registry. Am J Clin Nutr. 1999;69(6):1189-93.

13. Larson DE, Ferraro RT, Robertson DS, Ravus E. Energy metabolism in weight-stable postobese individuals. Am J Clin Nutr. 1995;62:735-9.

14. Ostendorf DM, Melanson EL, Caldwell AE, Creasy SA, Pan Z, MacLean PS, et al. No consistent evidence of a disproportionately low resting energy expenditure in long-term successful weight-loss maintainers. Am J Clin Nutr. 2018;108(4):658-66

15. Leibel RL, Rosenbaum M, Hirsch J. Changes in energy expenditure resulting from altered body weight. N Engl J Med. 1995;332:621-8.

16. Rosenbaum M, Hirsch J, Gallagher DA, Leibel RL. Long-term persistence of adaptive thermogenesis in subjects who have maintained a reduced body weight. Am J Clin Nutr. 2008;88(4):906-12.

17. Froidevaux F, Schutz Y, Christin L, Jequier E. Energy expenditure in obese women before and during weight loss, after refeeding, and in the weight-relapse period. Am J Clin Nutr. 1993;57(1):35-42.

18. Fothergill E, Guo J, Howard L, Kerns JC, Knuth ND, Brychta R, et al. Persistent metabolic adaptation 6 years after "The Biggest Loser" competition. Obesity (Silver Spring). 2016;24(8):1612-9.

19. Camps SG, Verhoef SP, Westerterp KR. Weight loss, weight maintenance, and adaptive thermogenesis. Am J Clin Nutr. 2013;97(5):990-4.

20. Johannsen DL, Knuth ND, Huizenga R, Rood JC, Ravussin E, Hall KD. Metabolic slowing with massive weight loss despite preservation of fat-free mass. J Clin Endocrinol Metab. 2012;97(7):2489-96.

21. Martins C, Gower BA, Hunter GR. Metabolic adaptation delays time to reach weight loss goals. Submitted.

22. Henry CJ, Lightowler HJ, Marchini J. Intra-individual variation in resting metabolic rate during the menstrual cycle. Br J Nutr. 2003;89(6):811-7.

23. Brennan IM, Feltrin KL, Nair NS, Hausken T, Little TJ, Gentilcore D, et al. Effects of the phases of the menstrual cycle on gastric emptying, glycemia, plasma GLP-1 and insulin, and energy intake in healthy lean women. Am J Physiol Gastrointest Liver Physiol. 2009;297(3):G602-10.

24. Curtis V, Henry CJ, Ghusain-Choueiri A. Basal metabolic rate of women on the contraceptive pill. Eur J Clin Nutr. 1996;50(5):319-22. 
25. Scheers T, Philippaerts R, Lefevre J. Patterns of physical activity and sedentary behavior in normal-weight, overweight and obese adults, as measured with a portable armband device and an electronic diary. Clin Nutr. 2012;31(5):756-64

26. Compher C, Frankenfield D, Keim N, Roth-Yousey L. Best practice methods to apply to measurement of resting metabolic rate in adults: a systematic review. J Am Diet Assoc. 2006;106(6):881-903.

27. Del Corral P, Chandler-Laney PC, Casazza K, Gower BA, Hunter GR. Effect of dietary adherence with or without exercise on weight loss: a mechanistic approach to a global problem. J Clin Endocrinol Metab. 2009;94(5):1602-7.

28. Brickwood KJ, Watson G, O'Brien J, Williams AD. Consumer-Based Wearable Activity Trackers Increase Physical Activity Participation: Systematic Review and Meta-Analysis. JMIR Mhealth Uhealth. 2019;7(4):e11819.

29. Forbes GB. Human body composition: growth, aging, nutrition, and activity. New York: Springer; 1987.

30. Spady DW, Payne PR, Picou D, Waterlow JC. Energy balance during recovery from malnutrition. Am J Clin Nutr. 1976;29(10):1073-88.
31. Jakicic JM, Otto AD, Lang W, Semler L, Winters C, Polzien K, et al. The effect of physical activity on 18-month weight change in overweight adults. Obesity (Silver Spring). 2011;19(1):100-9.

32. Forbes $\mathrm{GB}$. Body fat content influences the body composition response to nutrition and exercise. Ann N Y Acad Sci. 2000;904:359-65.

33. Goele K, Bosy-Westphal A, Rumcker B, Lagerpusch M, Muller MJ. Influence of changes in body composition and adaptive thermogenesis on the difference between measured and predicted weight loss in obese women. Obes Facts. 2009;2(2):105-9.

34. Borges JH, Carter SJ, Singh H, Hunter GR. Inverse relationship between changes of maximal aerobic capacity and changes in walking economy after weight loss. Eur J Appl Physiol. 2018;118(8):1573-8.

\section{Publisher's Note}

Springer Nature remains neutral with regard to jurisdictional claims in published maps and institutional affiliations.
Ready to submit your research? Choose BMC and benefit from:

- fast, convenient online submission

- thorough peer review by experienced researchers in your field

- rapid publication on acceptance

- support for research data, including large and complex data types

- gold Open Access which fosters wider collaboration and increased citations

- maximum visibility for your research: over $100 \mathrm{M}$ website views per year

At BMC, research is always in progress.

Learn more biomedcentral.com/submissions 